\title{
Knowledge, attitude and practice towards exclusive breast feeding among lactating mothers in a South Indian Hospital
}

\author{
Arunadevi. V. ${ }^{1}$, Viswanathan. S. ${ }^{2}$ \\ ${ }^{1}$ Dr. Arunadevi. V., Assistant Professor, ${ }^{2}$ Dr. Viswanathan. S., Professor; both authors are affiliated with Department of \\ Obstetrics \& Gynecology, Karpaga Vinayaga Institute of Medical Science and Research Centre, Madhuranthagam, \\ Tamilnadu, India.
}

Address for Correspondence: Dr. Arunadevi. V, Email: draruna83@gmail.com

\begin{abstract}
Background: Exclusive breast feeding (EBF) isconsidered when the infant does not receive any additional food or nutriment other than breast milk. Aims and Objectives: The object of the study was to assess knowledge, attitude and practice towards EBF among lactating mothers in a south Indian hospital. Materials and Methods: Thiscross-sectionalstudy was conducted among 300 mothers, attending outpatient department of a tertiary care hospital, Karpaga Vinayaga Institute of Medical Sciences over a period of one year. They were administereda structured questionnaire which sought such information as age, educationalstatus, occupation, initiation of breast feeding, prelacteal feeding and knowledge and practice of exclusive breast feeding. Results: Exclusive breast feeding was given for six months by $77.3 \%$ of study population. Their knowledge to start early breast feeding wasgood (57.7\%). Formula milk was the most commonly used top milk (25.7\%). Not enough breast milk (38\%) and baby didn't drink well (15.3\%) were the main reasons for stopping breastfeeding. Conclusion: Exclusive breastfeeding during approximately the first 6 months of life with continued breast feeding through at least the second half of infancy is associated with reduced risk of adverse outcomes in mother and infant.
\end{abstract}

Keywords: Exclusive breast feeding,Weaning,Knowledge, Attitude, Practice

\section{Introduction}

Breast feeding and breast milk are the global standard for infant feeding in undeveloped and developed countries. This statement is supported by the World Health Organization, the U.S. Surgeon General, the American Academy of Pediatrics [1], the American College of Obstetricians and Gynecologists [2], the American Academy of Family Practice, and the Academy of Breast feeding Medicine. The American Academy of Pediatrics has recently published an endorsement for breastfeeding at least through the first year of life and as an exclusive method for the first 6 months [1].

Specific populations are at greater risk for the failure to initiate and continue breast feeding. Woman of lower socioeconomic status, those with less education, and teenagers initiate breast feeding at about half to two thirds the rate of mature high-school graduates of middle and upper socioeconomic statuses [3, 4]. Fortunately, since 1989 more women at greatest risk for feeding their infants artificial breast milk are initiating breast feeding in the

Manuscript received: $16^{\text {th }}$ June 2017

Reviewed: $26^{\text {th }}$ June 2017

Author Corrected: $4^{\text {th }}$ July 2017

Accepted for Publication: $10^{\text {th }}$ July 2017

Obsgyne Review: Journal of Obstetrics and Gynecology
Hospital [4]. Human breast milk is uniquely suited to our biologic needs and remains the best source of nutrition for the human infant. Human breast milk has a composition very different than that of bovine milk or soybean plants from which artificial breast milk is produced [5]. Breast milk promotes optimal somatic growth and metabolic competence. Human breast milk is designed for more efficient and better digestion by the human infant than the bovine or soybean derived formula [5].

The nutritional differences between formula and human milk are reflected in differences in the growth patterns of infants who are exclusively breastfed for 4 to 6 months and infants who are fed formula artificial breast milk [6]. Breastfeeding enhances cognitive development. In highrisk premature neonates, human breast milk given by gavages in a dose-dependent fashion enhances the infant's later intelligence quotient (IQ) and performance on psychometric testing after controlling for maternal intelligence, family education, and socioeconomic status [7].Breast feeding enhances infant response to infection and reduces allergic disease. Breast milk has a wide array ofanti-infective properties that will support the developing immune system. The major mechanisms for the

Available online at : www.medresearch.in $\quad 44$ | P a g e 
protectiveproperties of breast milk include active leukocytes, antibodies, antibacterial products, competitive inhibition, enhancement of nonpathogenic commensal organisms and suppression of proinflammatory immune responses [8]. Our aim for this study is to determine the knowledge, attitude and practice of mother towards exclusive breast feeding and the barriers that deprive mother from giving breast feeding.

\section{Materials and Methods}

Research design: After obtaining institutional ethical clearance, we conducted this observational study in Karpaga Vinayaga Institute of medical sciences, Tamil Nadu from September 2015 to September 2016. Three hundred mothers attending post-natal outpatient department were randomly selected. The awareness about benefits and practices of breastfeeding surveyed was a population based on cross sectional study of lactating mothers $(n=300)$ who delivered at KIMS \& RC.

The study design incorporated both quantitative and qualitative methodologists to meet the aim in-depth descriptive information about knowledge, attitudeand practices of breastfeeding. A structured interviewer administered questionnaire was used to collect data on sociodemo-graphic characteristics, attribute of breast feeding and the obstacles that deprive mother from giving breast feeding. The questionnaire was designed consisting of three parts: Part A: Sociodemographic characteristics, Part B: KAP of exclusive breastfeeding and Part C:
Breastfeeding problems. Questionnaires were mixed with open-ended and closed ended questions.

Sample and Setting: This was a cross sectional descriptive study involving women of child bearing age who were currently breastfeeding at the time of the study or who had stopped breastfeeding not later than two years before (Inclusion Criterion) while mothers who never breastfed or were temporary visitors to the hospital were excluded from the study(exclusion criteria).

Data collection and Instruments: Data was collected using a comprehensive, pre-tested and structured interviewer-administered questionnaire which sought information as age, occupation, educational status, initiation of breastfeeding, prelacteal feeding \& knowledge, attitude practice of EBF.

Procedure for Data Analysis: The data gathered were analyzed using descriptive and inferential statistics. The data analyses were analyzed into three parts of premises, which were the demographic details of the respondents, KAP of exclusive breastfeeding and barriers encountered for initiation of breastfeeding. Demographic details were analyzed through 4 premises, KAP of breastfeeding was measured through 16 premises and breast feeding problems were analyzed through 4 premises.

Limitations: The study did not explore the cultural determinants of breastfeeding which might have some influence on EBF.

\section{Results}

The majorities of the participants in the study (37.7\%) were between 20-25 years and had two or more children (55.7\%).

Table-1: Sociodemographic characteristics of study participants $(n=300)$.

\begin{tabular}{|l|c|c|c|}
\hline \multicolumn{2}{|c|}{ Characteristics } & Frequency & Percentage \\
\hline \multirow{3}{*}{$\begin{array}{l}\text { 1. Maternal age } \\
\text { years) }\end{array}$} & $<20$ & 65 & $21.7 \%$ \\
\cline { 2 - 4 } & $21-25$ & 113 & $37.7 \%$ \\
\cline { 2 - 4 } & $26-30$ & 92 & $30.6 \%$ \\
\hline \multirow{4}{*}{ 2. Maternal occupation } & $>31$ & 30 & $10 \%$ \\
\cline { 2 - 4 } & Govt employee & 98 & $32.7 \%$ \\
\cline { 2 - 4 } & House wife & 117 & $39 \%$ \\
\cline { 2 - 4 } & Daily laborer & 64 & $21.3 \%$ \\
\hline \multirow{3}{*}{\begin{tabular}{l} 
education \\
\cline { 2 - 4 }
\end{tabular}} & Student & 21 & $7 \%$ \\
\cline { 2 - 4 } & Can't read & 50 & $16.7 \%$ \\
\cline { 2 - 4 } & Read\&write & 90 & $30 \%$ \\
\cline { 2 - 4 } & $1-8$ yr & 62 & $20.6 \%$ \\
\hline \multirow{3}{*}{ 4. Number of children } & $9-12 \mathrm{yr}$ & 57 & $19 \%$ \\
\cline { 2 - 4 } & College & 41 & $44.3 \%$ \\
\hline
\end{tabular}


Table-2: KAP of exclusive breastfeeding.

Original Research Article

\begin{tabular}{|c|c|c|c|}
\hline \multicolumn{2}{|l|}{ Attribute of Breastfeeding } & \multirow{2}{*}{$\begin{array}{c}\text { Number } \\
280 \\
20 \\
\end{array}$} & \multirow{2}{*}{$\begin{array}{c}\text { Percentage } \\
93.3 \% \\
6.7 \% \\
\end{array}$} \\
\hline 1) Ever heard about EBF? & $\begin{array}{l}\text { Yes } \\
\text { No }\end{array}$ & & \\
\hline \multirow[t]{3}{*}{ 2) Source of Information about EBF? } & Health Institution & 195 & $65 \%$ \\
\hline & Friends & 37 & $12.3 \%$ \\
\hline & Mass media & 68 & $22.7 \%$ \\
\hline \multirow[t]{4}{*}{ 3) Knowledge of time of starting Breast feeding. } & Within 1 hour & 173 & $57.7 \%$ \\
\hline & $1-4$ hours & 82 & $27.3 \%$ \\
\hline & 1-3 days & 35 & $11.7 \%$ \\
\hline & 1 week & 10 & $3.3 \%$ \\
\hline \multirow{4}{*}{$\begin{array}{l}\text { 4) Practiceof time of } \\
\text { Starting Breastfeeding. }\end{array}$} & Within 1 hour & 98 & $32.7 \%$ \\
\hline & $1-4$ hours & 142 & $47.3 \%$ \\
\hline & 1-3days & 38 & $12.7 \%$ \\
\hline & 1 week & 22 & $7.3 \%$ \\
\hline \multirow{2}{*}{$\begin{array}{l}\text { 5) Whether Exclusive } \\
\text { Breastfeeding given? }\end{array}$} & Yes & 268 & $89.3 \%$ \\
\hline & No & 32 & $10.7 \%$ \\
\hline \multirow{5}{*}{$\begin{array}{l}\text { 6) Duration of Exclusive } \\
\text { Breastfeeding given. }\end{array}$} & 3 months & 34 & $11.3 \%$ \\
\hline & 6 months & 232 & $77.3 \%$ \\
\hline & 9 months & 22 & $7.4 \%$ \\
\hline & 12 months & 9 & $3 \%$ \\
\hline & 18 months & 3 & $1 \%$ \\
\hline \multirow[t]{2}{*}{ 7) KnowledgeaboutColostrums. } & Good & 246 & $82 \%$ \\
\hline & $\mathrm{Bad}$ & 54 & $18 \%$ \\
\hline \multirow{2}{*}{$\begin{array}{l}\text { 8) Whether prelacteals } \\
\text { Given. }\end{array}$} & Given & 31 & $10.3 \%$ \\
\hline & Not given & 269 & $89.7 \%$ \\
\hline \multirow{4}{*}{ 9) Topfeeding used. } & Formula milk & 77 & $25.7 \%$ \\
\hline & Packaged milk & 37 & $12.3 \%$ \\
\hline & Fresh cow's milk & 67 & $22.3 \%$ \\
\hline & None & 119 & $39.7 \%$ \\
\hline \multirow[t]{2}{*}{ 10)Does frequent sucking help for milk production? } & Yes & 234 & $78 \%$ \\
\hline & No & 66 & $22 \%$ \\
\hline \multirow{2}{*}{$\begin{array}{l}\text { 11) Howdid you know when there is adequate breast } \\
\text { milk? }\end{array}$} & If the baby is satisfied & 259 & $86.3 \%$ \\
\hline & $\begin{array}{l}\text { Ifthe baby slept after } \\
\text { feeding }\end{array}$ & 41 & $13.7 \%$ \\
\hline \multirow[t]{2}{*}{ 12) When was weaning started? } & 6 months & 273 & $91 \%$ \\
\hline & 1 year & 27 & $9 \%$ \\
\hline \multirow[t]{2}{*}{ 13) Was Breastfeeding continued after weaning? } & Yes & 287 & $95.7 \%$ \\
\hline & No & 13 & $4.3 \%$ \\
\hline \multirow{5}{*}{ 14) Frequency of Breastfeeding } & $1 \mathrm{hr}$ & 69 & $23 \%$ \\
\hline & $2 \mathrm{hr}$ & 110 & $36.7 \%$ \\
\hline & $3 \mathrm{hr}$ & 42 & $14 \%$ \\
\hline & $4 \mathrm{hr}$ & 14 & $4.7 \%$ \\
\hline & Whenever required & 65 & $21.6 \%$ \\
\hline \multirow{3}{*}{$\begin{array}{l}\text { 15) Does EBF for } 6 \text { months prevent child from } \\
\text { diarrhea? }\end{array}$} & Yes & 102 & $34 \%$ \\
\hline & No & 153 & $51 \%$ \\
\hline & Don'tknow & 45 & $15 \%$ \\
\hline \multirow[t]{3}{*}{ 16) Does EBF prevent pregnancy? } & Yes & 112 & $37.3 \%$ \\
\hline & No & 64 & $21.4 \%$ \\
\hline & Don't know & 124 & $41.3 \%$ \\
\hline
\end{tabular}


Original Research Article

KAP of exclusive breastfeeding is given is Table 2 . The majority 280 of study participants had received information about EBF (93.3\%). Although $57.7 \%$ had the knowledge to initiate breastfeed within one hour of delivery, only $32.7 \%$ started giving breastfeeding. A good number of patients (18\%) felt that colostrum is bad and 10.3\% gave prelacteals before starting breastfeeding. Those who didn't practice exclusive breastfeeding gave mainly Formula milk (25.7\%). The majority of mothers said frequent sucking is helpful for milk production (78\%). 86.3\% of mothers responded that there is adequate breast milk if the child is satisfied. Weaning as recommended was started from six months of age by $91 \%$ of mothers. They gave breastfeeding hourly (23\%), two hourly (36.7\%) intervalsor whenever required $(21.6 \%) .86 .3 \%$ of mothers responded that there is adequate breast milk if the child is satisfied. $34 \%$ of mothers knew that EBF for six months protects their child from diarrhea. $37.3 \%$ mothers replied that EBF can be used as a contraceptive.

Table 3 caters data about breastfeeding problems. Referred counselor for breastfeeding issues was usually a doctor (85\%). Not enough breast milk (38\%) was the main reason for discontinuing breastfeeding.

Table-3: Breastfeeding problems

\begin{tabular}{|c|c|c|c|}
\hline \multicolumn{2}{|c|}{ Questions } & Number & Percentage \\
\hline \multirow{3}{*}{$\begin{array}{l}\text { 1) Counselor to discuss } \\
\text { Breastfeeding issues }\end{array}$} & Doctor & 255 & $85 \%$ \\
\hline & Nurse & 25 & $8.3 \%$ \\
\hline & Relative & 20 & $6.7 \%$ \\
\hline \multirow{4}{*}{$\begin{array}{l}\text { 2) If stopped Breast feeding early, } \\
\text { reason for stopping }\end{array}$} & No Breast milk & 114 & $38 \%$ \\
\hline & Baby didn't drink & 46 & $15.3 \%$ \\
\hline & Mother become sick & 16 & $5.3 \%$ \\
\hline & Don't stop BF & 124 & $41.4 \%$ \\
\hline \multirow[t]{4}{*}{ 3) Mother's satisfaction about BF } & Fully satisfied, & 236 & $78.7 \%$ \\
\hline & First satisfied not now & 42 & $14 \%$ \\
\hline & $\begin{array}{l}\text { Initially not } \\
\text { but later yes }\end{array}$ & 13 & $4.3 \%$ \\
\hline & Satisfied & 9 & $3 \%$ \\
\hline \multirow[t]{4}{*}{ 4) Duration of burping after BF } & 5 minutes & 118 & $39.3 \%$ \\
\hline & 15 minutes & 87 & $29 \%$ \\
\hline & 30minutes & 33 & $11 \%$ \\
\hline & Till burping & 62 & $20.7 \%$ \\
\hline
\end{tabular}

\section{Discussion}

The gynecologist plays a primary role in the initiation of breastfeeding [9]. Obstetric intervention is often critical for the health of the mother or infant, and they may affect the success of lactation [10]. Caesarean delivery reduces the incidence of breastfeeding by $10 \%$ to $20 \%$ in the first week after birth. After most cesarean sections and difficult vaginal deliveries, the infant is not put to the breast immediately after birth nor will the mother breastfeedher infant more than eight times in the first 24 hours [11]. The frequency of early feeding is proportional to milk production and weight gain in neonates [12]. Therefore, supplementation with glucose or formula should be discouraged. Supplementation also undermines the mother's confidence about her lactational adequacy $[13,14]$.

Recently, newer population research designs reduce the self selection bias. Cluster randomized trials of breastfeeding promotion intervention modeled on the WHO / UNICEF Baby - Friendly Hospital initiative [14] Obsgyne Review: Journal of Obstetrics and Gynecology have been used in two separate populations [15,16]. In these studies, maternity clinics and hospitals are assigned randomly to receive intensive educational programs to increase breastfeeding rates. The outcomes of interest are breastfeeding rates and short-term neonatal morbidities (infections, atopic dermatitis, etc). In both studies, breastfeeding rates were improved significantly $(\mathrm{P}<$ 0.001 ) with exclusive feeding at 3 months, $43.4 \%$ Versus $6.4 \%$ in Belarus[15] and $79 \%$ versus $48 \%$ in India [16]. The interventions were associated with $30 \%$ to $50 \%$ lower prevalence of gastrointestinal infections and atopic dermatitis and better infant growth.

Breastfeeding is beneficial to the health of the maternalinfant dyad; it improves psychosocial interactions, reduces economic burdens, and is valuable to society. The Agency for Health Care Research and Quality (AHRQ) published the "Evidence Report on Breastfeeding and Maternal and Infant Health Outcomes in Developed Countries, "which provides sufficient data to conclude

Available online at : www.medresearch.in 47 | $\mathrm{P}$ a g e 
Original Research Article

that the beneficial aspects of breastfeeding are substantial [17]. The report summarizes the link between breast feeding and reductions in acute morbidity and long termmorbidity. The data specifically suggest a doseresponse relationship between breastfeeding and reductions in otitis media, respiratory tract infections, asthma, bronchiolitis, atopic dermatitis, gastroenteritis, inflammatory bowel disease, celiac disease, diabetes, leukemia, and mortality (sudden infant death syndrome)[18]. Additional data support reductions in maternal cardiovascular disease with breastfeeding[19]. Mothers also benefit from exclusive breastfeeding by delays in menses and favorable postpartum weight $\operatorname{loss}[20,21]$.

Breastfeeding is influenced by economic and political forces. A nested case-control study in 2002 to 2003 of preterm birth and low birth weight among working women in Southern California found that provision of maternity leave is associated with about one-fourth of the risk of cesarean delivery, adjusted for covariates (odds ratio $0.27 ; 95 \%$ confidence interval, $0.08-0.94$ )[22]. An assessment of the literature on the length of maternity leave and health of mothers and children found a positive ecological association between the length of maternity leave and mother's mental health and duration of breastfeeding, as well as with lower perinatal, neonatal and post neonatal mortality and lower child mortality [23].

An Australian study found that returning to work in the first 10 months postpartum is associated with shorter breastfeeding durations [24]. Although the study mothers, who were drawn from a nationally distributed, selfselected consumer opinion panel, were not nationally representative, they characterized the population of US women most likely to succeed with breastfeeding [25], thus underscoring the need for effective strategies to enable more women to reach their exclusive breastfeeding goals. More than $85 \%$ of expectant mothers recruited for the national 2005-2007 Infant Feeding Practices Study II[25] (IFPS II) intended to exclusively breastfeed for 3 months or longer[27], yet, only $32 \%$ of mothers achieved their intended exclusive breastfeeding goal[26]

A 2005 Cochrane review of intervention trials to promote the initiation of breastfeeding found that health education, especially needs-based, informal, repeat sessions, and peer support interventions, significantly increases breast feeding initiation rates among US economically disadvantaged mothers [27]. Clinicians are consistently identified by mothers as the trusted source for information and guidance regarding breast feeding. A survey was conducted by the AAP in 2004 regarding mothers' and clinicians' perspectives on breastfeeding counseling during preventive visits [28]. The prospective cohort study of low-risk mothers in a large multispecialty group practice reported that although nearly all obstetric (91\%) and pediatric (97\%) clinicians said they usually/ always discuss plans to continue breastfeeding after returning to work, only $55 \%$ of the mothers reported that the topic was actually discussed. Only a few mothers reported discussing specific steps to maintain lactation after returning to work. These resultsindicate the gaps that the clinicians have in communicating effectively about the importance of breastfeeding and maintaining lactation.

\section{Conclusion}

Breastfeeding is cost-effective for the family and society. There had been a steady decline in the incidence of breastfeeding over the years. In the western developed countries, fewer women have been breastfeeding their infants. The cultural attitudes in the western world, and the need to get back to work for career women have contributed to this decline but even in India, mistaken notions about the practice of breastfeeding adversely affecting body form (breast shape) and the publicity regarding formula feeds as being superior in composition to breast milk have led the affluent classes to abandon attempts to breastfeed their babies.

The medical profession and the nursing profession have recognized the benefits of breast feeding, particularly in the developing world, and there is a concerted effort by social and medical organization to revive the practice of breastfeeding.

\section{Abbreviations}

EBF-Exclusive Breast Feeding, KAP- Knowledge, Attitude, Practices, WHO- World Health Organization UNICEF-United Nations International, Children Emergency Fund

Acknowledgement- Author acknowledges the enormous help received from the scholars whose articles have been cited and incorporated in references. Author is also grateful to author's editors / publishers of all those articles, journals and books from where the literature for this articlehas been reviewed and discussed.

Funding: Nil, Conflict of interest: Nil Permission from IRB: Yes

\section{References}

1. Section on Breastfeeding. Breastfeeding and the use of human milk. Pediatrics. 2012 Mar; 129(3):e827-41. doi: 10. 1542 /peds.2011-3552. Epub 2012 Feb 27. 


\section{Original Research Article}

2. Committee on Health care for Underserved Women, American College of Ob/Gyn, Breast feeding: Maternal and Infant Aspect ACOG Committee Opinion, 361, February 2007.

3. Scanlon KS, Grummer, Strawn L, Chen J, et al. Racial and ethnic differences in breastfeeding initiation and duration, by State - National immunization survey. United States, 2004- 2008. MMWR 59: 327, 2010.

4. Ahluwalia IB, Morrow B, Hsia J, Grummer-Strawn LM. Who is breast-feeding? Recenttrends from the pregnancyrisk assessment and monitoring system. J Pediatr. 2003 May;142(5):486-91.

5. Newton ER. Breastmilk: the gold standard. ClinObstet Gynecol. 2004 Sep;47(3):632-42.

6. Dewey KG. Growth characteristics of breastfedcompared to formula-fedinfants. Biol Neonate. 1998; 74(2): 94-105.

7. Lucas A, Morely R, Cole TJ: Randomized trial of early diet in preterm babies and later intelligence quotient. BMJ 31: 1481, 1999.

8. Hanson LA. Human milk and hostdefence: immediate and long-term effects. Acta Paediatr Suppl. 1999 Aug;88 (430): 42-6.

9. Dettuwyler KA: A time to wean: the hominid blueprint for the natural age of weaning in modern human populations. In Stuart. MacAdanP, Dettwyler KA (eds): Breast feeding: Biocultural Perspectives, New York, Aldine de Gruyter,1995.

10. Dewey KG, Nommsen-Rivers LA, HeinigMJ, Cohen RJ. Risk factors for suboptimalinfant breastfeeding behavior, delayedonset of lactation, and excessneonatal weight loss. Pediatrics. 2003 Sep;112(3 Pt 1):607-19.

11. Patel RR, Liebling RE, Murphy DJ. Effect of operative delivery in the secondstage of labor on breastfeeding success. Birth. 2003 Dec; 30 (4): 255-60.

12. Egli GE, Egli NS, Newton M. The influence of the number of breast feedings on milkproduction. Pediatrics. 1961 Feb; 27:314-7.

13. Howard C, Howard F, Lawrence R, Andresen E, DeBlieck E, Weitzman M. Office prenatal formula advertising and its effect on breast-feedingpatterns. Obstet Gynecol. 2000 Feb;95(2):296-303.
14. WHO / UNICEF: Protesting, Promoting, and supporting breastfeeding: The special role of maternity services, a joint WHO/ UNICEF statement. Geneva, World Health Organization, 1989.

15. Kramer MS, Chalmers B, Hodnett ED, Sevkovskaya Z, Dzikovich I, Shapiro S, Collet JP, Vanilovich I, Mezen I, Ducruet T, Shishko G, Zubovich V, Mknuik D, Gluchanina E, Dombrovskiy V, Ustinovitch A, Kot T, Bogdanovich N, Ovchinikova L, Helsing E. PROBIT Study Group (Promotion of Breastfeeding Intervention Trial). Promotion of Breastfeeding Intervention Trial (PROBIT): a randomizedtrial in the Republic of Belarus. JAMA. 2001 Jan 24-31;285(4):413-20.

16. Bhandari N, Bahl R, Mazumdar S, Martines J, Black RE, Bhan MK; Infant Feeding Study Group. Effect of community-basedpromotion of exclusive breastfeeding on diarrhoeal illness and growth: a clusterrandomised controlled trial. Lancet. 2003 Apr 26; 361 (9367): 1418-23.

17. IP S, Chung M, Raman G, Chew P, Magula N, DeVine D, Trikalinos T, Lau J. Breastfeeding and maternal and infant healthoutcomes in developed countries. Evid Rep Technol Assess (Full Rep). 2007 Apr; (153):1-186.

18. Eidelman AI,Schanler RJ. American Academy of Pediatrics, Section on Breast-feeding Executive Committee. Breastfeeding and the use of human milk.Pediatrics 2012; 129: e827-41.

19. Schwarz EB, Ray RM, Stuebe AM, Allison MA, Ness RB, Freiberg MS, Cauley JA. Duration of lactation and risk factors for maternalcardiovascular disease. Obstet Gynecol. 2009 May; 113(5): 974-82. doi: 10.1097/01. AOG. 0000346884.67796.ca.

20. Eidelman AI,Schanler RJ.Section on breastfeeding executive committee.Breastfeeding and the use of human milk:executive summary.Pediatrics 2012;129:598-601.

21. Hauck FR, Thompson JM, Tanabe KO, Moon RY, Vennemann MM. Breastfeeding and reduced risk of sudden infant death syndrome: a meta-analysis. Pediatrics. 2011 Jul; 128(1):103-10. doi: 10.1542/peds.2010-3000. Epub 2011 Jun 13.

22. Guendelman S, Pearl M, Graham S, Hubbard A, Hosang N, Kharrazi M. Maternity leave in the ninthmonth of pregnancy and birthoutcomes among working women. Womens Health Issues. 2009 Jan-Feb;19(1):30-7. doi: 10.1016/j.whi.2008.07.007. 


\section{Original Research Article}

23. Staehelin K, Bertea PC, Stutz EZ. Length of maternity leave and health of mother and child--a review. Int $\mathrm{J}$ Public Health. 2007;52(4):202-9.

24. Cooklin AR, Rowe HJ, Fisher JR. Paid parental leave supports breastfeeding and mother-infant relationship: a prospective investigation of maternal postpartum employment. Aust N Z J Public Health. 2012 Jun; 36(3): 249-56. doi: 10.1111/j.1753-6405.2012. 00846. x. Epub $2012 \mathrm{Feb} 23$.

25. Fein SB, Labiner-Wolfe J, Shealy KR, Li R, Chen J, Grummer-Strawn LM. Infant Feeding Practices Study II: study methods. Pediatrics. 2008 Oct;122 Supp12:S28-35. doi: $10.1542 /$ peds.2008-1315c.
26. Perrine CG, Scanlon KS, Li R et al.Baby-Friendly hospital practices and meeting exclusive breastfeeding intention.Pediatrics 2012;130:54-604.PM:22665406.

27. Dyson L,McCormick F,Renfrew MJ.Interventions for promoting the initiation of breastfeeding.Cochrane Database Syst Rev 2005:CD001688.PM:15846621.

28. Taveras EM, Li R, Grummer-Strawn L, Richardson M, Marshall R, Rêgo VH, Miroshnik I, Lieu TA. Mothers' and clinicians' perspectives on breastfeedingcounseling during routinepreventive visits. Pediatrics. 2004 May; 113 (5):e405-11.

\section{How to cite this article?}

Arunadevi. V, Viswanathan. S. Knowledge, attitude and practice towards exclusive breast feeding among lactating mothers in a South Indian Hospital. Obs Rev:J obstet Gynecol 2017;3(4):44-50.doi:10.17511/joog.2017.i04.03. 